\title{
New Goods and Economic Growth: Evidence from Legalized Gambling
}

\section{Douglas M. Walker and John D. Jackson*}

\begin{abstract}
We address two questions: (1) Does legalized gambling spur economic growth? and, if so, (2) Does economic growth depend on "exports?" After developing a method of applying Granger causality to panel data, we analyze the casino gambling and greyhound racing industries. Empirical results suggest the answer to (1) is "yes." Both industries Granger cause economic growth. Because of the industry-wide results, the alleged "factory-restaurant dichotomy" for casino gambling does not appear to be valid. Based on the disparate thresholds and ranges of the industries and the consistent causal results (both industries Granger cause per capita income) the answer to question (2) appears to be "no."
\end{abstract}

\section{INTRODUCTION}

Over the last half-century, policies that promote economic growth have become an integral part of public sector economic activity at the state level. State government attempts to attract industry via tax breaks and financial incentives have been the object of considerable research attention, past and present. But the apparent inability of either of these sets of policies to sustain successful outcomes over time has led state policy makers to explore alternative avenues. Writing in the 1930s, Joseph Schumpeter (1934) noted that one method of spurring economic growth is to provide a new good to the consuming public. Since legalization of a previously illegal activity is tantamount to introducing a "new good" to the public's menu of consumption possibilities, there should be no surprise that a state growth policy that has seen increasing recent popularity is the legalization of gambling activities.

The past two decades have witnessed a literal explosion of state legalization of betting on horse racing, dog racing, lotteries, casino games, etc. Currently, every state except Utah and Hawaii has some form of legal gambling (Kaplan 1992), and each year some states consider legalizing additional types of gambling. Since gambling (locally provided, at least) is often considered a "bad" by the state's electoral majority, some offsetting benefit attendant to its provision must be offered to justify its legalization. That benefit, politicians argue, is the expansion of state economic growth resulting from increased (export or local) spending, tax revenues, and employment.

Opponents of legalized gambling offer a two-pronged argument against legalization. First, they argue that there are tremendous social costs associated

*Professor, Department of Economics and Finance, Georgia College and State University and Professor, Department of Economics, Auburn University. The authors would like to thank two anonymous reviewers for their helpful comments. Of course, we are responsible for any remaining errors. 
with the provision of gambling. ${ }^{.}$Second, they assert that the economic growth motivation for legalization is specious. ${ }^{2}$ While many analysts have addressed the issue of social costs, the question of whether legalizing particular gaming activities leads to economic growth has not been subjected to rigorous scrutiny.

Empirical analysis of legalized gambling, with the possible exception of state-run lotteries, has received very little attention from economists. One explanation for this absence, or at least paucity, of prior research is that, in most states, legalization of gambling has occurred only in the past decade. Consequently, data have been scarce. While some researchers have looked at particular states' experiences with legalized gambling, most offer only casual observation as their evidence. ${ }^{3}$ To our knowledge, no author has offered a comprehensive analysis of the relationship between gambling legalization and economic growth.

The purpose of this paper is to empirically test the effects of legalizing gambling on economic growth. The analysis proceeds as follows: Section II fleshes out the empirical question and provides background for its application to two of the major types of gambling - casinos and greyhound racing. Section III presents the methodology we employ to test our hypotheses. Specifically, we use Granger causality techniques to test whether casino gambling causes growth or conversely, and we perform an analogous set of tests for gambling at greyhound racetracks. Because we must pool time series data on several states to conduct each of our analyses, the application of Granger's approach to analyzing causality is not straightforward. The results of our empirical analysis are presented and discussed in Section IV. The paper concludes with a brief summary.

\section{II. "FACTORY-RESTAURANT" DICHOTOMY AND EXPORT-BASE THEORY APPLIED TO LEGALIZED GAMBLING}

Empirical research on legalized gambling is extremely limited. However, many authors casually discuss the issue, and most of these argue that the introduction of gambling does not cause growth. Their argument goes as follows: It is necessary to draw money from outside the state (i.e., to export the service to tourists) in order for the provision of gambling activities to lead to economic growth. Most types of gambling are not characterized by the ability to draw consumers over long distances, so that spending on gambling is primarily by local consumers. As such, spending on newly legalized gambling completely crowds out spending on alternative locally produced goods, leading to no increase in state-level total spending. Thus, from a growth perspective, legalized gambling is at best a zero-sum game. This is an export-base theory of growth.

\footnotetext{
"For discussions of the "social costs" associated with legalized gambling, see Boreham, Dickerson, and Harley (1996), "Casinos in Florida" (1995), Goodman (1994a; 1994b; 1995a; 1995b), Grinols (1995), Grinols and Omorov (1996), Gross (1998a; 1998b), Kindt (1994; 1995), LaFalce (1994), Ladd (1995), Politzer, Morrow, and Leavey (1985), Tannenwald (1995), Thompson, Gazel, and Rickman (1997), and U.S. House (1995). For an economic perspective on these "social costs," see Walker and Barnett (1998).

${ }^{2}$ The economic growth aspects of legalized gambling are discussed in many of the articles listed in note 1. In addition to those, see Eadington (1995; 1996), Grinols (1994a; 1994b), Rose (1995), Thompson (1996), and Wright (1995).

${ }^{3}$ For a review of much of this research, see Walker (1998a).
} 
Grinols (1994b) explains exactly why he believes casino gambling will not lead to economic growth in most cases. He generally accepts the export-base argument as valid, and questions whether the casino industry can always be expected to export. In Nevada, for example, casinos act as "factories" because they sell their services to people around the country and world; tourists are critical to the Nevada markets. However, in most markets, casinos are likely to act only as "restaurants." That is, their revenues are simply at the expense of other local businesses; there are no exports to tourists.

Grinols' "factory-restaurant dichotomy" does make some intuitive sense. However, it is clear that exports cannot be the sole determinant of economic growth. The obvious example is the world economy, which has grown enormously without exporting anything. ${ }^{4}$ If exports are not, in fact, the sole determinant of growth, then many of the conclusions in the legalized gambling literature must be reconsidered.

This debate over legalized gambling and economic growth hinges crucially on the implications of two testable hypotheses:

(1) "Does the introduction of legalized gambling lead to economic growth for the state?" and, given an affirmative answer,

(2) "Is it necessary to export gambling in order to obtain this result?"

Our purpose in this paper is to provide answers to these questions through empirical testing of the relationship between state economic growth and two industries: casino gambling and greyhound racing. Answers to these questions will address the more general question of whether introducing a new good into an economy tends to cause economic growth.

The factory-restaurant dichotomy is related to the first question. If the dichotomy is valid, (i.e., if casinos can be factories in a few states but only restaurants in most others) then we should expect no consistent industry-wide results.

We chose casino gambling and greyhound racing-industries with different market thresholds (i.e., the minimum number of consumers required to support the industries) and ranges-to address the second question, regarding the export-base theory. The casino industry likely has a much larger threshold and range than does the greyhound racing industry. Consider that casinos keep a much lower percentage of consumers' bets, about $2-5 \%$ on average. Racetracks, on the other hand, keep about $18-20 \%$ of each dollar bet. The fact that casinos keep much less of each dollar bet indicates that it has a much higher threshold compared to greyhound racing. This, coupled with the fact that casinos' net revenues are, on average, many times larger than racetracks', suggests that the casinos draw from a much larger range. For a given export range, even if casinos draw substantially more local customers than greyhound tracks, the casinos draw a much higher revenue, and most likely export in a greater magnitude. Advertising and "clustering" patterns support this conclusion. There are many nationwide adver- 
tisements, for example, by Las Vegas, Atlantic City, and Mississippi casinos. Casinos hope to attract tourists from afar. Such national advertisements for greyhound racing are extremely rare, although it is often advertised locally. In addition, casinos often cluster together. Such agglomeration economies are not to be expected unless the producers are selling in a national market. This provides anecdotal evidence that the industries themselves view the range of casino gambling as much greater (i.e., national) than that for greyhound racing (regional at most).

We are not suggesting that casinos export and that greyhound racing does not. Even the smallest crossroads gasoline station exports when an out-of-state automobile stops for gas. Rather, we are suggesting that a consistent finding that both activities "cause" growth indicates that exports may not be a fundamental factor in generating that growth due to the starkly different thresholds and ranges of the two goods. Specifically, a comparison of the empirical results for the two industries will help us to answer the second question posed. If the casino industry causes growth, but the greyhound industry does not, then we may conclude that exports have a significant impact on economic growth, since the industry with the much smaller range did not show evidence of driving economic growth. On the other hand, if both industries have a similar positive impact on growth, then we may conclude that exports may not be crucial, since even with little or no export base, greyhound racing is found to be an engine for growth. The third possible finding is that greyhound racing causes growth but casinos do not. This result would be difficult to explain. Of course there is a fourth possibility, that neither industry has a significant impact on growth.

In the next section we consider problems that arise when we attempt to empirically test these hypotheses by applying Granger causality testing techniques in an unconventional setting.

\section{METHODOLOGY: GRANGER CAUSALITY ANALYSIS WITH PANEL DATA}

Alternatively testing the dual hypotheses that casino revenues cause state economic growth and greyhound racing handle (bets) cause state economic growth can provide important information regarding the two questions posed in the previous section. While there exists no precise way to establish the direction of causal behavior, statistical causality has been defined and several tests developed for its presence. The definition and test of choice in the recent economics literature seem to be those suggested by Granger (1969).

Certainly Granger causality has proved a useful means of evaluating the potential sources of aggregate economic growth in recent empirical work. Jung and Marshall (1985) consider the relationship between exports and growth; Joerding (1986) and Kusi (1994) analyze the relationship between military spending and economic growth; Conte and Darrat (1988) look at the size of the government sector and economic growth; and Ramirez (1994) has shown that real government 
investment Granger causes real private investment in Mexico. This wide applicability makes Granger causality a natural technique to employ in our causal inquiry.

Granger's methods, however, are not directly applicable to the problems at hand. These techniques were originally intended to apply to a set of linear, covariance-stationary time series processes. This suggests that we should test for Granger causality on gambling revenue and per capita income on a state-by-state basis. Unfortunately (for our study, at least), only two of the ten states with legal (non-reservation) casino gambling had this activity prior to 1990, and fully two-thirds of the states having legal greyhound racing adopted it post-1985. Thus, establishing the requisite stationarity on a state-by-state basis and appealing to the asymptotic properties of a number of the associated estimators and tests cannot be justified due to the brevity of the time series on the gambling activities available for most states. For this reason we pool our data for each activity, creating a panel consisting of a time series of observations for each of a cross section of states.

The statistical analysis of panel data using time series methods is still in its infancy. Although it may have been applied in the past by statisticians, we are aware of only one paper, Holtz-Eakin, Newey, and Rosen (1988), that relates directly to the estimation and testing of vector auto-regressive models, such as those needed to apply Granger's procedure, to panel data. In addition, there have been several recent studies that look at the related problem of unit roots in panel data. Works by Breitung and Meyer (1994), Frances and Hobjin (1997), MacDonald (1996), Strazicich (1995), and Wu (1996) fall into this category.

\section{Synopsis of Granger's procedure}

The application of Granger causality to panel data is not straightforward. Thus, we will briefly review the general methodology of Granger causality and then discuss in detail the modifications we impose in order to apply it to our panel data problem.

According to Granger, a variable $\left\{X_{t}\right\}$ causes another variable $\left\{Y_{t}\right\}$ if, given a universe of information on all factors affecting both $\left\{X_{t}\right\}$ and $\left\{Y_{t}\right\}$, the current value of $Y$ (i.e., $Y_{t}$ ) can be predicted more accurately using past values of $X$ (i.e., $X_{t-}$ $j, j=1, \ldots, J)$ than by not using them. More precisely, define $\left\{A_{t}\right\}$ as the set containing all possible information affecting $\left\{Y_{t}\right\}$, except information on $\left\{X_{t}\right\}$. Also define the mean square (prediction) error of $Y_{t}$ given $A_{t}$ as $\sigma^{2}\left(Y_{t} \mid A_{t}\right)$. "Granger causality" states that $X$ causes $Y$ if

$$
\sigma^{2}\left(Y_{t} \mid A_{t}, X_{t}\right)<\sigma^{2}\left(Y_{t} \mid A_{t}\right)
$$

Since adding a statistically significant set of variables reduces the error variance in a least squares regression context, traditional $\mathrm{t}$ - and F- tests are available to test for the presence of Granger causality.

The testing procedure is straightforward. Assuming $\left\{X_{t}\right\}$ and $\left\{Y_{t}\right\}$ are a pair of linear covariance stationary processes, they can be written as 


$$
\begin{aligned}
& X_{t}=\sum_{j=1}^{k} \alpha_{j} X_{t-j}+\sum_{j=1}^{m} \beta_{j} Y_{t-j}+\epsilon_{1, t} \\
& Y_{t}=\sum_{j=1}^{r} \gamma_{j} Y_{t-j}+\sum_{j=1}^{s} \delta_{j} X_{t-j}+\epsilon_{2, t}
\end{aligned}
$$

where $\alpha_{j}, \beta_{j}, \gamma_{j}$ and $\delta_{j}$ are unknown parameters to be estimated, and $\epsilon_{1, t}$ and $\epsilon_{2, t}$ are white noise disturbance terms. Applying least squares regression techniques to estimate these two models yields four types of Granger causality tests: (i) $X$ causes $Y$ if $\mathrm{H}_{0}: \delta_{1}=\delta_{2}=\ldots=\delta_{\mathrm{s}}=0$ can be rejected; (ii) $\mathrm{Y}$ causes $\mathrm{X}$ if $\mathrm{H}_{0}: \beta_{1}=\beta_{2}=\ldots=\beta_{\mathrm{m}}=0$ can be rejected; (iii) if both null hypotheses can be rejected, feedback (simultaneous determination of $X$ and $Y$ ) is indicated; and (iv) if neither null hypothesis is rejected, $X$ and $Y$ are independent.

Typical caveats for the procedure relate to the structure of the hypothesis tests (one actually rejects Granger non-causality rather than accepting Granger causality) and to whether variables other than lagged values of $\left\{Y_{t}\right\}$ should be included in $\left\{A_{t}\right\} .{ }^{5}$ The most important caveat, however, relates to stationarity of the two series. Without stationarity, common trends could result in two spurious regressions having perverse causality implications, such as business cycles causing sunspots [see Sheehan and Grieves (1982) and Noble and Fields (1983)]. Wold's theorem tells us that a stationary time series process can always be written as the sum of a self-deterministic component and a moving average component of possibly infinite order (Granger 1980, p. 60). Thus, if $\left\{Y_{t}\right\}$ is stationary, it is possible for $\left\{A_{t}\right\}$ to include only its past values thereby eliminating the ambiguity in specifying $\left\{\mathrm{A}_{t}\right\}$ noted above.

\section{Modifying the procedure for panel data}

As we suggested earlier, the extension of these procedures to pooled time series cross section data is not straightforward, but our data paucity problem necessitates the use of this type of model. Consequently, we use a three-stage procedure: (i) filtering trend and state-specific effects from the data; and (ii) selecting the appropriate time series process that generates each variable. After making these adjustments we can (iii) conduct the Granger causality tests.

Stage 1

Perhaps the best way to visualize the problems involved and to understand our attempted solutions is to consider the way that we array the data on each variable used in our analysis. Consider a general gambling revenue variable, $\mathrm{REV}_{\text {it }}$ (Later we examine our specific variables, casino revenue [CR], greyhound handle [HAN], and per capita income [PCI].) We have i states $(\mathrm{i}=1, \ldots, \mathrm{I})$ with legalized gambling and $t$ time periods $(t=1, \ldots, T)$ of observations on a particular state.

${ }^{5}$ It is perfectly legitimate to include variables other than lagged values of $X_{t}$ and $Y_{t}$ in the two regressions (for example, see Conte and Darrat [1988]). But including such variables "muddies the causality waters" since $X$ could cause $Y$ through affecting some other included variables, rather than directly. 
In all of the subsequent analyses, we "stack" these data by state, and within each state we organize the data in ascending order of time. Thus, it is routine to find the last observation of state i revenue, $\mathrm{REV}_{\mathrm{iT}}$, followed by the first observation for state (i+1), $\operatorname{REV}_{\mathrm{i}+1,1}$. The following discussion of filtering the data should make it clear that the order in which the states are stacked is not a matter of concern, but the obvious discontinuities involved in proceeding from the last period's observations in one state to the first period's observation in the next, requires some adjustment in the ordinary time series methodology.

The most obvious adjustment is filtering out state-specific and trend effects from the vector of observations on $R V_{i t}$. We pursue this requirement by regressing $R E V_{\text {it }}$ on: (1) a constant term; (2) a set of (I-1) state dummy variables (to account for state specific effects); (3) a time trend ( $t=1$ is the beginning observation for each state) to account for a common trend in the data; and (4) interaction variables computed by multiplying each state dummy by the trend variable (to allow for different trends for each state). If the data are quarterly, seasonal adjustment (via including a set of quarterly dummies) is also appropriate at this stage. Finally, a dummy variable equal to unity for the first observation of a new state is included to promote continuity of the pooled variable. The residual from this regression, $\mathrm{REV}_{\text {rit }}$, should be free from state-specific trend and other idiosyncratic anomalies. We refer to this residual as the filtered series.

At this stage of the analysis, it is appropriate to test the filtered series for stationarity. Recall the primacy of stationarity as a condition for the legitimate application of Granger's causality tests; it is no less so here. ${ }^{6} \mathrm{~A}$ number of procedures are available to test for the presence of stationarity or lack thereof, as denoted by the presence of a unit root in the series: Dickey-Fuller, augmented Dickey-Fuller, and Phillips-Perron are three popular unit root tests. Since our filtered revenue series is a detrended, zero mean series, our choice among these alternative tests is not likely to be crucial. Nevertheless, we opt for the PhillipsPerron test since it is robust with respect to the number of lagged differenced variables included in the test equation. If our unit root tests allow us to reject nonstationarity, we proceed to the next step in our analysis; otherwise we continue to respecify the filtering equation until we are able to reject non-stationarity.

Our modifications so far serve three purposes. First, filtering out unspecified state-specific effects and state-specific trend effects should eliminate any concern about the order in which the state data are stacked, particularly since the filtered measure is stationary. Second, filtering out trend effects should eliminate any concern that our results are attributable to a common trend between our revenue and income variables. Third, stationarity of the filtered series guarantees that any innovation in our series, whether state specific or attributable to another time-independent factor, is of temporary duration. Thus, ruling out (or, at least,

${ }^{6}$ This may be an overstatement. Holtz-Eakin, Newey and Rosen (1988, p. 1373) suggest that a large number of cross sections make it possible for lag coefficients to vary over time. Of course, there is always the question of how large is "large." We view it as unlikely that the eight to fourteen cross sections that we deal with here are "large" numbers. 
reducing the likelihood of) permanent shocks, common trend, and common factor problems gives us reason to believe that any causality we may find between gambling revenue and per capita income is not caused by exogenous forces.

\section{Stage 2}

Since our filtered revenue series and similarly filtered income series are stationary, the next step is to determine as precisely as possible what autoregressive process generates each series. ${ }^{7}$ This stage amounts to a strict application of Box-Jenkins procedures to each filtered variable. Our intent is to continue to add lags in the variables to the specification of the generating process until we obtain a white noise residual. We employ correlograms and partial correlograms to aid in specifying the generating process, along with Box-Pierce $Q$-statistics to detect white noise residuals. Here parsimony is our guide: we wish to choose the shortest possible set of lags such that no significant (at the $\alpha=0.10$ level) autocorrelations exist among the residuals, as judged by $Q$-statistics for the first thirty-six lags.

While this step is not traditional, it is done with a purpose. If we can identify the process generating, say, the filtered income series, so that the residuals of the estimated process are white noise, we can be reasonably certain that we have extracted all possible information on the current value of the variable from its past values. There is no temporally systematic effect left to explain. Then, if (lagged values of) a new variable, say, filtered revenue, is added to the model and if it provides a statistically significant improvement in explaining filtered income, it is legitimate to claim that revenue "causes" income. This stage does introduce a problem concerning lagging the data that comes to fruition in the third stage of our analysis. We now turn to an examination of that stage.

Stage 3

The second stage of our analysis provided us with all the information we need to accurately specify the regression equations. The final stage of our analysis is to estimate the vector autoregressions implied by Granger causality testing and to perform the requisite hypothesis tests. Assuming that the second stage indicated that filtered per capita income $\left(\mathrm{PCIr}_{\mathrm{it}}\right)$ was generated by an $\mathrm{AR}(\mathrm{p})$ process and filtered revenue $\left(\mathrm{REVr}_{\mathrm{it}}\right)$ was generated by an $\mathrm{AR}(\mathrm{m})$ process, the sequels to equations (2) and (3) are

$$
\begin{aligned}
& \operatorname{PCIr}_{i, t}=\sum_{j=1}^{p} \alpha_{j} P C I r_{i, t-j}+\sum_{j=1}^{m} \beta_{j} \operatorname{REVr}_{i, t-j}+\epsilon_{1, t} \\
& \operatorname{REVr}_{i, t}=\sum_{j=1}^{m} \gamma_{j} \operatorname{REVr}_{i, t-j}+\sum_{j=1}^{p} \delta_{j} P C I r_{i, t-j}+\epsilon_{2, t}
\end{aligned}
$$

'Technically, all Wold's theorem guarantees us is that a stationary series can be specified by an ARMA process. While a moving average error process cannot be ruled out $a$ priori, it turns out for our problem that adding enough lagged terms will yield a white noise residual in all cases. 
The corresponding hypothesis tests are $\mathrm{H}_{0}: \beta_{1}=\beta_{2}=\ldots=\beta_{\mathrm{m}}=0$ to test whether REVr Granger causes PCIr, and $\mathrm{H}_{0}: \delta_{1}=\delta_{2}=\ldots=\delta_{\mathrm{P}}=0$ to test whether PCIr Granger causes REVr. The models are estimated by ordinary least squares regression ${ }^{8}$ and the tests are standard $F$-tests of the joint hypotheses.

We conclude our discussion of the modifications of traditional Granger causality analysis deriving from the use of panel data with consideration for an important, if pedestrian, point mentioned earlier. Lagging variables uses up considerably more degrees of freedom than one might first expect because of the stacked nature of panel data. If we lag the data, say, three periods to estimate the appropriate autoregressive process in stage two, we lose $3 I$ (not 3 ) degrees of freedom when employing panel data on $I$ states. The reason we lose $3 I$ observations, rather than the 3 we would normally lose is that each state's data must be lagged three periods. The reason for these extra lags is not statistical; recall that we establish at stage one that the process is stationary. Rather, the extra lags are economically motivated: it makes no economic sense to allege that the early period observations (say $t=1,2,3$ ) in state $i+1$ are explained by the later period observations (say $T-2$, $T-1, T)$ in state $i$. But that is precisely what we assume does happen if we do not drop the first three observations for state $i+1$, and similarly for all other states. Thus, the gain in degrees of freedom from pooling time series and cross-sectional data may not be nearly as much as one might expect at first blush.

This problem is even more exaggerated at stage three of our analysis. If $R E V r$ is found to be, say, $\mathrm{AR}(m)$ and $\mathrm{PCI} r$ is found to be, say, $\mathrm{AR}(p)$ from stage two, where $p>m$, then we must drop the first $p$ observations from each state, after lagging, so as not to have an economically meaningless set of parameter estimates for equations (4) and (5). This means that, inter alia, for a state to remain in the model after the filtering stage, it must have at least $p+1$ observations. ${ }^{9}$ This, in turn, implies an iterative procedure between our three stages of analysis until a useable sample of data can be determined.

Clearly, the application of Granger causality techniques to panel data is not altogether straightforward. Nonetheless, we believe that a careful analysis along the lines outlined above can provide reliable and useful information concerning causal relationships between state gaming revenues and economic growth. We now turn to our empirical analysis of these questions.

\section{EMPIRICAL TEST RESULTS}

Certainly consumers' welfare is enhanced by the availability of new goods and services. But do these new opportunities have a measurable effect on economic growth? Legalized gambling provides a unique opportunity to test this. If industries with different ranges are tested and compared, we can evaluate the importance of exports on economic growth. Using the methodology developed in

Since the explanatory variables are the same for both models, there is no difference between OLS and seemingly unrelated regression estimates, whether or not $\epsilon_{1, t}$ is correlated with $\epsilon_{2, t^{*}}$

${ }^{9} \mathrm{~A}$ state would be thrown out of the model in the filtering stage if $n<k$, where $k$ is the number of explanatory variables in the filtering equation, excluding other states' dummy and interaction variables. 
the previous section, we present the empirical results for the casino gambling and greyhound racing industries.

\section{Casino gambling}

Quarterly real casino revenue and real per capita income data were initially collected on ten states, listed with beginning year and quarter. ${ }^{10}$ Data on all states run through the fourth quarter of 1996 (i.e., 1996.4): Colorado (1991.4), Illinois (1992.3), Indiana (1995.4), Iowa (1992.4), Louisiana (1993.4), Mississippi (1992.3), Missouri (1994.3), Nevada (1985.1), New Jersey (1978.2), and South Dakota (1991.3). A total of 248 observations are available. Because casino gambling is a relatively new industry in most states, there are not enough observations to analyze each state individually. A first pass through our procedure indicated that estimating the Granger causality equations would require a ten-quarter lag (i.e., dropping ten observations per state.) Since Indiana had only five observations and Missouri eleven, we drop both states from the model. There are 232 observations on the other eight states' casino revenue $(C R)$ and per capita income $(P C I)$.

The first step in our application is to filter the series, as illustrated in the following regressions:

$$
\begin{aligned}
& \mathrm{PCI}_{t}=\varphi_{1}+\varphi_{2} \mathrm{Q} 1+\varphi_{3} \mathrm{Q} 2+\varphi_{4} \mathrm{Q} 3+\varphi_{5} \mathrm{Tr}+\varphi_{6} \mathrm{New}+\varphi_{7} \mathrm{PCId}+\varphi_{8} \mathrm{COd}+ \\
& \varphi_{9} \mathrm{COi}+\varphi_{10} \mathrm{ILd}+\varphi_{11} \mathrm{ILi}+\varphi_{12} \mathrm{IAd}+\varphi_{13} \mathrm{IAi}+\varphi_{14} \mathrm{LAd}+\varphi_{15} \mathrm{LAi}+\varphi_{16} \mathrm{MSd}+ \\
& \varphi_{17} \mathrm{MSi}+\varphi_{18} \mathrm{NVd}+\varphi_{19} \mathrm{NVi}+\varphi_{20} \mathrm{NJd}+\varphi_{21} \mathrm{NJi}+\iota_{1, t} \\
& \mathrm{CR}_{\mathrm{t}}=\kappa_{1}+\kappa_{2} \mathrm{Q} 1+\kappa_{3} \mathrm{Q} 2+\kappa_{4} \mathrm{Q} 3+\kappa_{5} \mathrm{Tr}+\kappa_{6} \mathrm{New}+\kappa_{7} \mathrm{COd}+\kappa_{8} \mathrm{COi}+ \\
& \kappa_{9} \mathrm{ILd}+\kappa_{10} \mathrm{ILi}+\kappa_{11} \mathrm{Idd}+\kappa_{12} \mathrm{IAi}+\kappa_{13} \mathrm{LAd}+\kappa_{14} \mathrm{LAi}+\kappa_{15} \mathrm{MSd}+\kappa_{16} \mathrm{MSi}+ \\
& \kappa_{17} \mathrm{NVd}+\kappa_{18} \mathrm{NVi}+\kappa_{19} \mathrm{NJd}+\kappa_{20} \mathrm{NJi}+\iota_{2, \mathrm{t}}
\end{aligned}
$$

As previously explained, a state dummy (e.g., COd for Colorado) for all but one of the states should remove any effects from stacking the data and from fixed effect, state-specific differences in measurement. A time trend (Tr) and quarterly dummy variables $(Q 1, Q 2, Q 3)$ are included to remove any timedependent trends or seasonal components that might be included in the processes. Seven state-trend interaction terms (e.g., $\mathrm{CO} i$ for Colorado) are used to remove any state-specific trends in the data. South Dakota is the state lacking the dummy and interaction variables; it is the base state. Because stacking the data for the states results in a "spike" at the first observation of a new state, we add a "first year" dummy variable (i.e., the first observation for each state is $1 ; 0$ for all other observations) called New). Since per capita income data come from two different sources, we add a dummy variable (PCId) for observations prior to 1990 to distinguish the sources and to account for any recording differences from those sources. This dummy affects only Nevada and New Jersey in the per capita income filtering equation. Finally, $\iota_{1, t}$ and $\iota_{2, t}$ are stochastic disturbances.

${ }^{10}$ Quarterly per capita income data were calculated using personal income data (Department of Commerce) and linearly interpolated annual Census population estimates. 
The results from estimating these filtering regressions are presented in Tables $1 \mathrm{a}$ and $1 \mathrm{~b}$. (All tables are located in the appendix.) Testing the filtered variables, $P C I r$ and $C R r$, for unit roots we find that the Phillips-Perron $(P P)$ test indicates both series to be stationary at the $1 \%$ level $\left(\mathrm{PP}_{\mathrm{CRr}}=-8.324 ; \mathrm{PP}_{\mathrm{PCIr}}=-4.594\right.$; critical value $=-2.575$ ). The next step is to determine the time series process that generates each of the filtered variables. Box-Jenkins methods indicate that PCIr can legitimately be viewed as being generated by an $A R(7)$ process and $C R r$ by an $A R(9)$. The estimated processes are presented in Tables $2 a$ and $2 b$. Note that for the remainder of our procedure, we must drop the higher lag-number of observations (i.e., 9) from each state. This leaves us with 160 total observations, compared to 232 in the original model specification.

Finally, we alternately regress the stationary filtered series, PCIr and CRr, on their own respective lagged values and on past values of the other variable, and then test whether the coefficients on the other variable's lags are (jointly) significantly different from zero. Defining $C$ as a constant term, we estimate

$$
P C I r_{i, t}=C+\sum_{j=1}^{7} \Psi_{j} P C I r_{i, t-j}+\sum_{j=1}^{9} \pi_{j} C R r_{i, t-j}+\mu_{1, t}
$$

and for filtered casino revenue,

$$
\mathrm{CRr} r_{i, t}=\mathrm{C}+\sum_{j=1}^{9} \tau_{j} \mathrm{CRr}_{\mathrm{i}, \mathrm{t}-\mathrm{j}}+\sum_{\mathrm{j}=1}^{7} \lambda_{\mathrm{j}} \mathrm{PCIr_{i,t-j }}+\mu_{2, t}
$$

The estimation and joint test results are presented in Tables $3 a$ and $b$. In the case of (8), we test $\mathrm{H}_{0}: \pi_{1}=\pi_{2}=\ldots=\pi_{9}=0$. If we reject the null hypothesis, then casino revenue Granger causes economic growth. Failure to reject the null means there is no evidence of a causal relationship in this direction. For (9), we test $\mathrm{H}_{0}: \lambda_{1}=\lambda_{2}=\ldots=\lambda_{7}=0$. Analogous to the case above, rejection of the null implies economic growth Granger causes casino gambling. Failure to reject would imply increased per capita income does not cause increases in casino revenues. Since we can reject the former null hypothesis but not the latter, the results in Table $3 \mathrm{c}$ indicate that casino revenue Granger causes economic growth (significant at the $1 \%$ level) and not conversely.

Several points concerning these results are worthy of note. First, as many politicians and the casino industry suggest, the product does have a positive effect on growth. We have taken precautions to ensure that Nevada does not dominate the empirical results. Recall that data on Nevada are included only back until 1985, while New Jersey goes back to its beginning, 1978, and all other states to theirs, the early 1990s. Furthermore, when the model is split and component models are tested, the results are consistent with those presented in Table 3c. ${ }^{11}$ Second, with regard to the factory-restaurant dichotomy, the entire industry appears to be a factory - not just Nevada, as Grinols (1994b) has suggested. If Nevada, New

${ }^{11}$ For example, we tested NJ and MS together and found the same result as in Table $3 \mathrm{c}$. A full discussion can be found in Walker (1998a). 
Jersey, and Mississippi are the only factories, we would not expect such significant results in the overall model, since the other alleged restaurant states comprise about half of the observations (107 of 232 before sample adjustment, 78 of 160 after) in the model. If there did not exist a causal relationship in these states, we would expect this to add sufficient variation to the model to prevent us from rejecting the hypothesis of non-causality.

The results in this section should not be expected merely because gambling revenues are theoretically a component of per capita income. If that reasoning was valid, we should have found Granger causality in the other direction as well. Simply because two variables may be expected to move in the same direction over time does not imply that one detrended variable is causing the other.

Overall, these results suggest that there is a positive causal relationship from the introduction of legalized casino gambling (a new good) to economic growth. Comparing this result to the results of similar tests on greyhound racing will give us better information on the validity of the export-base theory of economic growth.

\section{Greyhound racing}

The legalization of greyhound racing was not as explosive as that of casino gambling. In some states racing has been legal since the 1930s, while others have legalized it as recently as the 1980s. Annual data were collected on the per capita income and gross handle (i.e., dollar amount of bets placed at the tracks) for greyhound racing in 18 states. ${ }^{12}$ In most cases, the greyhound data were supplied by the individual states' racing commissions. For those states whose commissions were uncooperative, data were found in the Annual Statistical Summary of Pari-Mutuel Racing, published by the Association of Racing Commissioners International.

We repeat the procedure to analyze the greyhound racing industry. Variables included in the filtering equations were a constant, trend, the New variable, and the state dummy and trend-dummy interaction terms, all described above. Of course, we employ no quarterly dummies here since the data are annual. Initially, there were 222 observations on the 18 states. Preliminary tests for proper lag length yielded a number that required that four states be dropped from the model for lack of sufficient observations: Kansas, Texas, Vermont, and Wisconsin. Each of these states had only five to seven observations. The end result is a pooled data set covering fourteen states and consisting of 195 observations. The states included are listed below, along with the first year of data for each state: Alabama (Mobile and Birmingham counties only; 1975), Arizona (1984), Arkansas (1975), Colorado (1985), Connecticut (1985), Florida (1985), Idaho (1985), Iowa (1985), Massachusetts (1985), New Hampshire (1975), Oregon (1975), Rhode

\footnotetext{
${ }^{12}$ Annual data are used here primarily because quarterly are not available. This does not cause complications, however, because greyhound racing has been legal much longer (generally) than casino gambling.
} 
Island (1985), South Dakota (1982), and West Virginia (1985). Data were collected through 1995. As in the casino tests, the data used in this model were adjusted for inflation.

The estimated filtering equations for handle (HAN) and PCI are presented in Tables $4 \mathrm{a}$ and $4 \mathrm{~b}$. The Phillips-Perron test statistic on HANr is -7.97 , and on PCIr, the statistic is -6.35 . With a critical value at the $1 \%$ level of -2.58 , the hypothesis of a unit root can be rejected for both series.

A Box-Jenkins analysis of the filtered residuals indicates that PCIr was generated by an AR(4) process and HANr by an AR(3). Estimates of these models are displayed in Tables $5 \mathrm{a}$ and $5 \mathrm{~b}$. The final step is to conduct our Granger causality test. This involves estimating the following models and conducting the requisite F-tests.

$$
\mathrm{PCI}_{\mathrm{i}, \mathrm{t}}=\mathrm{C}+\sum_{\mathrm{j}=1}^{4} \Theta_{\mathrm{j}} \mathrm{PCIr}_{\mathrm{i}, \mathrm{t}-\mathrm{j}}+\sum_{\mathrm{j}=1}^{3} \zeta_{\mathrm{j}} \mathrm{HANr}_{\mathrm{i}, \mathrm{t}-\mathrm{j}}+v_{1, t}
$$

$$
\mathrm{HANr}_{\mathrm{i}, \mathrm{t}}=\mathrm{C}+\sum_{\mathrm{j}=1}^{3} \phi_{\mathrm{j}} \mathrm{HANr}_{\mathrm{i}, \mathrm{tj}}+\sum_{\mathrm{j}=1}^{4} \eta_{\mathrm{j}} \mathrm{PCIr}_{\mathrm{i}, \mathrm{t}-\mathrm{j}}+v_{2, t}
$$

The results from the regressions and F-tests are presented in Tables 6a-c. The result that greyhound handle Granger causes per capita income is significant at standard levels. There is no evidence of bilateral causality.

As with the casino gambling model, we attempted to investigate whether a single state or small group of states is responsible for the results. We split the sample into two component parts, one with states that have had greyhound racing for a relatively long period of time, e.g., back through 1975, the other with states that had only more recently legalized the activity. Both sets of analyses exhibited results highly consistent with those of Table $6 \mathrm{c}$. For the long series states, the F-statistic for testing the null hypothesis that HANr does not cause PCIr was 4.77 and the F-statistic for testing the null that PCIr does not cause HANr was 0.70 . For the short series, the respective F-values were 7.30 and $0.93 .{ }^{13}$

\section{SUMMARY AND CONCLUSIONS}

Effusive rhetoric continually surrounds attempts by state governments to legalize various gaming activities. The forces in favor of legalization argue that, among other potential advantages, the new gambling activity will promote state economic growth. Opponents argue that the economic growth argument is without merit. Typically neither side offers any empirical evidence in support of their claims.

We have tested two hypotheses that address the economic growth effects of legalizing gambling: (1) Does legalized gambling contribute to state economic growth? If so, (2) Is it necessary for gambling to be exported for economic growth to result? We have addressed these questions using a Granger causality analysis 
of panel data on casino gambling, greyhound racing, and per capita income at the state level.

We can conclude that casino gambling and greyhound racing Granger cause state per capita income (that is, we reject the hypotheses that casino and greyhound gambling do not Granger cause state per capita income). We find no evidence that causality also runs in the other direction. These results obviously suggest that the answer to question (1) is "yes." We can also address the legitimacy of the factory-restaurant dichotomy in the case of casino gambling. There is no evidence that the dichotomy is valid. If it were valid, we would not have found industry-level results of any significance.

Moreover, our results imply that adding a new good to a state's consumption menu does indeed spur state economic growth. (Certainly, we have no evidence to the contrary in this analysis.)

Regarding question (2), the export-base theory, recall that the two gambling activities have disparate thresholds and ranges. Based on our results, it does not appear that exports play the crucial role that they often are alleged to play in the state growth process. This latter inference is not intended to suggest that exporting goods and services does not result in state economic growth. After all, casino gambling has both a threshold and range exceeding the size of the states where casinos are offered, and we found that it causes state economic growth. On the other hand we found the same results for greyhound racing, which has a much smaller threshold and range. We conclude that exporting the newly legalized gambling activity may be a sufficient, but not necessary, condition for its provision to result in state economic growth.

While we have addressed the question of whether growth results from legalized gambling, we have not attempted to explain the channels through which the legalization of a gambling activity translates into economic growth. Is it the construction of casinos and racetracks that expand a state's capital stock? (Perhaps there is a redistribution of income from consumers with high MPCs [losers] to entrepreneurs with lower MPCs [winners], resulting in a continually expanding capital stock.) Is it the immigration attendant to the higher wages attributable to this expanded state infrastructure? Is it an increase in the velocity of spending resulting from consumers having an additional product to purchase? Is it the result of a Keynesian-type government spending multiplier effect attributable to what the state does with its additional revenue? Exactly how does legalized gambling spur economic growth? This question warrants attention now that there is empirical evidence of a relationship between the variables. 


\section{APPENDIX}

TABLE 1A

Filtering equation for per capita income (PCI)-casino states

\begin{tabular}{lrr}
\hline Variable & Coefficient & t-Statistic \\
\hline C & 11757.000 & 71.233 \\
Q1 & -18.438 & -0.277 \\
Q2 & 1.687 & 0.026 \\
Q3 & -38.778 & -0.596 \\
Tr & 84.200 & 6.953 \\
New & 147.854 & 1.057 \\
PCId & 529.542 & 4.279 \\
COd & 2959.865 & 13.113 \\
COi & -17.102 & -0.972 \\
IAd & 928.215 & 3.863 \\
IAi & 20.673 & 0.966 \\
ILd & 3893.260 & 16.505 \\
ILi & -6.028 & -0.299 \\
LAd & 215.164 & 0.817 \\
LAi & -21.512 & -0.736 \\
MSd & -1735.818 & -7.359 \\
MSi & -8.739 & 0.433 \\
NJd & 1122.577 & 4.617 \\
NJi & 19.188 & 1.543 \\
NVd & 2073.391 & 8.727 \\
NVi & -29.582 & -2.250 \\
\hline
\end{tabular}

Sample: 1-39 45-92 104-248

$\mathrm{n}=232 \quad$ S.E. of regression $=356.862$

$\mathrm{R}^{2}=0.980 \quad$ F-statistic $=504.692$

Adjusted $R^{2}=0.978$

TABLE 1B

Filtering equation for casino revenue (CR)

\begin{tabular}{lrc}
\hline Variable & $\begin{array}{c}\text { Coefficient } \\
\text { (millions) }\end{array}$ & t-Statistic \\
\hline C & -6.059 & -0.205 \\
Q1 & 6.200 & 0.522 \\
Q2 & 23.636 & 2.000 \\
Tr & 57.265 & 4.928 \\
New & -0.555 & -0.257 \\
COd & -68.385 & -2.743 \\
COi & 27.119 & 0.672 \\
IAd & 1.638 & 0.521 \\
IAi & -2.233 & -0.052 \\
Ild & 3.017 & 0.789 \\
ILi & 61.911 & 1.469 \\
LAd & 8.197 & 2.273 \\
LAi & 62.004 & 1.317 \\
MSd & 11.648 & 2.223 \\
MSi & 68.228 & 1.618 \\
NJd & 15.116 & 4.191 \\
NJi & 207.000 & 6.474 \\
NVd & 6.940 & 3.172 \\
NVi & 765.000 & 22.581 \\
Li & 9.392 & 4.163 \\
\hline
\end{tabular}

Sample: 1-39 45-92 104-248

$n=232 \quad$ S.E. of regression $=63779653$

$R^{2}=0.973 \quad$ F-statistic $=398.204$

Adjusted $R^{2}=0.970$ 
TABLE 2A

Estimated generating process (PCIr)-casino states

\begin{tabular}{lcc}
\hline Variable & Coefficient & t-Statistic \\
\hline C & -4.424 & -0.331 \\
PCIr(-1) & 0.791 & 10.403 \\
PCIr(-2) & 0.140 & 1.477 \\
PCIr(-3) & -0.013 & -0.136 \\
PCIr(-4) & -0.023 & -0.247 \\
PCIr(-5) & -0.062 & -0.669 \\
PCIr(-6) & 0.201 & 2.245 \\
PCIr(-7) & -0.136 & -1.915 \\
\hline
\end{tabular}

Sample: 8-21 29-39 52-61 69-74 82-92 111-151 159-226 234-248

$\mathrm{n}=176 \quad$ S.E. of regression $=176.200$

$\mathrm{R}^{2}=0.778 \quad$ F-statistic $=84.009$

Adjusted $R^{2}=0.769$

TABLE 2B

Estimated generating process $(\mathrm{CRr})$

\begin{tabular}{lrc}
\hline Variable & Coefficient & t-Statistic \\
\hline$C$ & -2805153.000 & -0.815 \\
$C R r(-1)$ & 0.911 & 6.725 \\
$C R r(-2)$ & 0.289 & 1.876 \\
$C R r(-3)$ & -0.110 & -0.714 \\
$C R r(-4)$ & 0.175 & 1.185 \\
$C R r(-5)$ & -0.275 & -1.800 \\
$C R r(-6)$ & -0.358 & -2.421 \\
$C R r(-7)$ & 0.185 & 1.191 \\
$C R r(-8)$ & 0.591 & 3.969 \\
$C R r(-9)$ & -0.531 & -4.335 \\
\hline
\end{tabular}

Sample: 10-21 31-39 54-61 71-74 84-92 113-151 161-226 236-248

$\mathrm{n}=160 \quad$ S.E. of regression $=40672677$

$R^{2}=0.593 \quad$ F-statistic $=\mathbf{2 4 . 2 3 8}$

Adjusted $R^{2}=0.568$

TABLE 3A

PCIr model (CRr causes PCIr)

\begin{tabular}{lrc}
\hline Variable & Coefficient & t-Statistic \\
\hline C & -16.315 & -1.064 \\
PCIr(-1) & 0.680 & 8.242 \\
PCIr(-2) & 0.103 & 1.048 \\
PCIr(-3) & -0.012 & -0.120 \\
PCIr(-4) & -0.028 & -0.295 \\
PCIr(-5) & -0.016 & -0.171 \\
PCIr(-6) & 0.208 & 2.238 \\
PCIr(-7) & -0.075 & -0.956 \\
CRr(-1) & 0.000 & 1.591 \\
CRr(-2) & 0.000 & 0.089 \\
CRr(-3) & -0.000 & -0.073 \\
CRr(-4) & -0.000 & -1.422 \\
CRr(-5) & 0.000 & 1.043 \\
CRr(-6) & -0.000 & -1.051 \\
CRr(-7) & 0.000 & 2.016 \\
CRr(-8) & 0.000 & 0.911 \\
CRr(-9) & -0.000 & -0.866 \\
\hline
\end{tabular}

Sample: 10-21 31-39 54-61 71-74 84-92 113-151 161-226 236-248

$\mathrm{n}=160 \quad$ S.E. of regression $=171.581$

$\mathbf{R}^{2}=0.818 \quad$ F-statistic $=40.225$

Adjusted $R^{2}=0.799$ 
TABLE 3B

$\mathrm{CRr}$ model ( $\mathrm{PCI}$ causes $\mathrm{CRr}$ )

\begin{tabular}{lrr}
\hline Variable & Coefficient & t-Statistic \\
\hline C & 2484047.000 & -0.674 \\
CRr(-1) & 0.939 & 6.612 \\
CRr(-2) & 0.296 & 1.851 \\
CRr(-3) & -0.123 & -0.774 \\
CRr(-4) & 0.167 & 1.111 \\
CRr(-5) & -0.278 & -1.771 \\
CRr(-6 & -0.376 & -2.465 \\
CRr(-7) & 0.186 & 1.157 \\
CRr(-8) & 0.603 & 3.891 \\
CRr(-9) & -0.576 & -4.329 \\
PCIr(-1) & 9250.146 & 0.467 \\
PCIr(-2) & 3047.294 & 0.130 \\
PCIr(-3) & -16416.920 & -0.709 \\
PCIr(-4) & 16847.010 & 0.729 \\
PCIr(-5) & -6020.957 & -0.261 \\
PCIr(-6) & 21942.330 & 0.983 \\
PCIr(-7) & -17374.360 & -0.923
\end{tabular}

Sample: 10-21 31-39 54-61 71-74 84-92 113-151 161-226 236-248

$n=160 \quad$ S.E. of regression $=41250110$

$\mathrm{R}^{2}=\mathbf{0 . 6 0 0}$ F-statistic $=\mathbf{1 3 . 4 3 2}$

Adjusted $\mathrm{R}^{2}=0.556$

TABLE 3C

Casino model Granger causality F-test results

\begin{tabular}{rcc}
\hline Hypothesis & F-Statistic & Probability \\
\hline$\pi_{1}=\pi_{2}=\ldots \pi_{9}=0$ & 2.577 & 0.009 \\
$(\mathrm{CRr}$ does not cause $\mathrm{PCIr})$ & & \\
$\lambda_{1}=\lambda_{2}=\ldots . \lambda F_{9}=0$ & 0.404 & 0.898 \\
(PCIr does not cause $\mathrm{CRr}$ ) & & \\
\hline
\end{tabular}

TABLE 4A

Filtering equation for per capita income (PCI)-greyhound states

\begin{tabular}{lrr}
\hline Variable & Coefficient & t-Statistic \\
\hline C & 8585.535 & 43.457 \\
Tr & 142.372 & 9.070 \\
New & -442.234 & -3.246 \\
ALd & -28.762 & -0.104 \\
ALi & 40.416 & 1.832 \\
AZd & 3773.301 & 11.393 \\
AZi & -82.472 & -2.085 \\
COd & 5390.059 & 15.741 \\
COi & -8.983 & -0.203 \\
CTd & 9595.786 & 28.023 \\
CTi & 107.381 & 2.422 \\
FLd & 5229.023 & 15.271 \\
FLi & -42.447 & -0.957 \\
IAd & 3773.296 & 11.020 \\
IAi & -41.219 & -0.930 \\
IDd & 2654.403 & 6.767 \\
IDi & -3.963 & -0.057 \\
MAd & 8078.714 & 23.593 \\
MAi & -3.410 & -0.077 \\
NHd & 1970.871 & 7.116 \\
NHi & 180.362 & 8.177
\end{tabular}


TABLE 4A (continued)

\begin{tabular}{lrc} 
Variable & Coefficient & t-Statistic \\
\hline ORd & 2878.810 & 10.394 \\
ORi & -40.766 & -1.848 \\
RId & 5505.259 & 16.078 \\
RIi & -19.274 & -0.435 \\
SDd & 1269.565 & 4.051 \\
SDi & 70.188 & 2.144 \\
WVd & 1366.823 & 3.992 \\
WVi & 2.617 & 0.059 \\
\hline
\end{tabular}

Sample: 1-106 114-191 206-216

$n=195 \quad$ S.E. of regression $=432.814$

$R^{2}=0.978 \quad$ F-statistic $=265.866$

Adjusted $R^{2}=0.975$

TABLE 4B

Filtering equation for greyhound handle (HAN)

\begin{tabular}{lrr}
\hline Variable & $\begin{array}{r}\text { Coefficient } \\
\text { (millions) }\end{array}$ & t-Statistic \\
\hline C & 171.000 & 18.021 \\
Tr & -3.108 & -4.123 \\
New & -33.015 & -5.048 \\
ALd & -74.579 & -5.608 \\
ALi & 2.161 & 2.040 \\
AZd & 2.006 & 0.126 \\
AZi & -5.186 & -2.730 \\
COd & 55.414 & 3.371 \\
COi & -8.815 & -4.141 \\
CTd & -21.609 & -1.314 \\
CTi & -8.409 & -3.950 \\
FLd & 813.000 & 49.457 \\
FLi & -36.782 & -17.279 \\
IAd & 13.934 & 0.848 \\
IAi & -9.824 & -4.615 \\
IDd & 140.000 & -7.409 \\
IDi & 1.940 & -0.006 \\
MAd & 214.000 & 13.028 \\
MAi & -15.403 & -7.236 \\
NHd & 17.566 & 1.321 \\
NHi & -4.857 & -4.586 \\
ORd & -92.175 & -6.932 \\
ORi & 0.958 & 0.905 \\
RId & 3.834 & 0.233 \\
RIi & -8.935 & -4.198 \\
SDd & 126.000 & -8.395 \\
SDi & -0.392 & -0.249 \\
WVd & 15.424 & 0.938 \\
WVi & -8.505 & -3.995 \\
\hline
\end{tabular}

Sample: 1-106 114-191 206-216

$\mathrm{n}=195 \quad$ S.E. of regression $=20779597$

$\mathrm{R}^{2}=0.986 \quad$ F-statistic $=429.048$

Adjusted $R^{2}=0.984$ 
TABLE 5A

Estimated generating process (PCIr)-greyhound states

\begin{tabular}{lrc}
\hline Variable & Coefficient & t-Statistic \\
\hline C & -11.776 & -0.587 \\
PCIr(-1) & 0.861 & 10.715 \\
PCIr(-2) & -0.183 & -1.691 \\
PCIr(-3) & -0.087 & -0.819 \\
PCIr(-4) & -0.171 & -2.217 \\
\hline
\end{tabular}

Sample: 5-21 26-33 38-54 59-65 70-76 81-87 92-95 100-106 118-124 129-145 150-166 171-177 182-191 210-216

$n=139 \quad$ S.E. of regression $=236.242$

$\mathrm{R}^{2}=\mathbf{0 . 6 8 9} \quad$ F-statistic $=\mathbf{7 4 . 1 3 5}$

Adjusted $R^{2}=0.679$

TABLE 5B

Estimated generating process (HANr)

\begin{tabular}{lcc}
\hline Variable & Coefficient & t-Statistic \\
\hline C & -593122 & -0.872 \\
HANr(-1) & 1.104 & 16.693 \\
HANr(-2) & -0.494 & -6.215 \\
HANr(-3) & -0.060 & -1.190 \\
\hline
\end{tabular}

Sample: 4-21 25-33 37-54 58-65 69-76 80-87 91-95 99-106 117-124 128-145 149-166 170-177

181-191 209-216

$\mathrm{n}=153 \quad$ S.E. of regression $=8402286$

$R^{2}=0.761 \quad$ F-statistic $=157.954$

Adjusted $R^{2}=0.756$

TABLE 6A

PCIr model (HANr causes PCIr)

\begin{tabular}{lrc}
\hline Variable & Coefficient & t-Statistic \\
\hline C & -10.620 & -0.540 \\
PCIr(-1) & 0.803 & 9.853 \\
PCIr(-2) & -0.141 & -1.329 \\
PCIr(-3) & -0.048 & -0.455 \\
PCIr(-4) & -0.161 & -2.137 \\
HANr(-1) & 0.000 & 0.522 \\
HANr(-2) & -0.000 & -0.227 \\
HANr(-3) & -0.000 & -1.733 \\
\hline
\end{tabular}

Sample: 5-21 26-33 38-54 59-65 70-76 81-87 92-95 100-106 118-124 129-145 150-166 171-177

182-191 210-216

$\mathrm{n}=139 \quad$ S.E. of regression $=229.513$

$R^{2}=0.713 \quad$ F-statistic $=46.450$

Adjusted $R^{2}=0.697$ 
TABLE 6B

HANr model (PCIr causes HANr)

\begin{tabular}{lrc}
\hline Variable & Coefficient & t-Statistic \\
\hline C & -942522.000 & -1.275 \\
HANr(-1) & 0.986 & 11.072 \\
HANr(-2) & -0.373 & -3.215 \\
HANr(-3) & -0.121 & -1.499 \\
PCIr(-1) & -830.482 & -0.271 \\
PCIr(-2) & 2714.919 & 0.680 \\
PCIr(-3) & 2240.241 & 0.568 \\
PCIr(-4) & -2142.637 & -0.758 \\
\hline
\end{tabular}

Sample: 5-21 26-33 38-54 59-65 70-76 81-87 92-95 100-106 118-124 129-145 150-166 171-177

182-191 210-216

$\mathrm{n}=139 \quad$ S.E. of regression $=8634299$

$\mathrm{R}^{2}=0.720 \quad$ F-statistic $=\mathbf{4 8 . 1 6 1}$

Adjusted $R^{2}=0.705$

TABLE 6C

Greyhound model Granger causality F-test results

\begin{tabular}{rcc}
\hline Hypothesis & F-Statistic & Probability \\
\hline $\begin{array}{c}\zeta_{1}=\zeta_{2}=\zeta_{3}=0 \\
\text { (HANr does not cause PCIr) }\end{array}$ & 3.657 & 0.014 \\
$\eta_{1}=\eta_{2}=\eta_{3}=\eta_{4}=0$ & & \\
(PCIr does not cause HANr) & 0.841 & 0.501 \\
\hline
\end{tabular}

\section{REFERENCES}

Boreham, P., M. Dickerson, and B. Harley. "What are the Social Costs of Gambling?: The Case of the Queensland Machine Gaming Industry." Australian Journal of Social Issues 31 (1996), 425-442.

Breitung, J. and W. Meyer. "Testing for Unit Roots in Panel Data: Are Wages on Different Bargaining Levels Cointegrated?" Applied Economics 26 (1994), 353-361.

Conte, M.A. and A.F. Darrat. "Economic Growth and the Expanding Public Sector." Review of Economics and Statistics (1988), 322-330.

Eadington, W.R. "Calling the Bluff: Analyzing the Legalization of Casino-Style Gaming-A Comment on 'Bluff or Winning Hand? Riverboat Gambling and Regional Employment and Unemployment."' Reno, NV: Institute for the Study of Gambling \& Commercial Gaming, 1995.

. "The Legalization of Casinos: Policy Objectives, Regulatory Alternatives, and Cost/Benefit Considerations." Journal of Travel Research 34 (1996), 3-8.

Frances, P.H. and B. Hobijn. "Critical Values for Unit Root Tests in Seasonal Time Series." Journal of Applied Statistics 24 (1997), 25-47.

Goodman, R. Legalized Gambling as a Strategy for Economic Development. Northampton, MA: United States Gambling Study, 1994a.

- Testimony and Prepared Statement (1994b). In U.S. House of

Representatives, Committee on Small Business. The National Impact of Casino Gambling Proliferation (1995), 4-8 and 56-70. 
"Legalized Gambling: Public Policy and Economic Development Issues." Economic Development Review 13 (1995a), 55-57.

. The Luck Business: The Devastating Consequences and Broken Promises of America's Gambling Explosion. New York, NY: The Free Press, 1995b.

Granger, C.W.J. "Investigating Cảusal Relationships by Econometric Methods and Cross Spectral Methods." Econometrica 37 (1969), 424-438.

. Forecasting in Business and Economics. New York, NY: Academic Press, 1980.

Grinols, E.L. "Bluff or Winning Hand? Riverboat Gambling and Regional Employment and Unemployment." Illinois Business Review 51 (1994a), 8-11. . Testimony and Prepared Statement (1994b). In U.S. House of Representatives, Committee on Small Business. The National Impact of Casino Gambling Proliferation (1995), 8-11 and 71-76.

"The Impact of Casino Gambling on Income and Jobs." In R. Tannenwald (ed.), Casino Development: How Would Casinos Affect New England's Economy? Boston, MA: Federal Reserve Bank of Boston (1995), 3-17. Grinols, E.L. and J.D. Omorov. "Development or Dreamfield Delusions? Assessing

Casino Gambling's Costs and Benefits." Journal of Law and Commerce 16 (1996): 49-87.

Gross, M. "Legal Gambling as a Strategy for Economic Development." Economic Development Quarterly 12 (1998a), 203-213.

. "Response to a Comment on 'Legal Gambling as a Strategy for Economic Development.' " Economic Development Quarterly 12 (1998b), 217. Holtz-Eakin, D., W. Newey, and H.S. Rosen. "Estimating Vector Autoregressions with Panel Data." Econometrica 56 (1988), 1371-1395.

Hoover, E.M. and F. Giarratani. An Introduction to Regional Economics, 3rd ed. New York, NY: Alfred A. Knopf, 1984.

Joerding, M. "Economic Growth and Defense Spending." Journal of Economic Development 21(1986), 35-40.

Jung, W.S. and P.J. Marshall. "Exports, Growth, and Causality in Developing Countries." Journal of Economic Development 18 (1985), 1-12.

Kaplan, H.R. "The Effect of State Lotteries on the Pari-Mutuel Industry." In W.R.

Eadington and J.A. Cornelius (eds.), Gambling and Commercial Gaming: Essays in Business, Economics, Philosophy, and Science. Reno, NV: Institute for the Study of Gambling and Commercial Gaming (1992), 301-314.

Kindt, J.W. "The Economic Impacts of Legalized Gambling Activities." Drake Law Review 43 (1994), 51-95.

"U.S. National Security and the Strategic Economic Base: The Business/Economic Impacts of the Legalization of Gambling Activities." Saint Louis University Law Journal 39 (1995), 567-584.

Kusi, N.K. "Economic Growth and Defense Spending in Developing Countries." Journal of Conflict Resolution 38 (1994), 152-159. 
LaFalce, J.J. Opening Statement. In U.S. House of Representatives, Committee on Small Business. The National Impact of Casino Gambling Proliferation (1995), $1-4$ and $37-41$.

Ladd, H.F. "Introduction to Panel III: Social Costs." In R. Tannenwald (ed.), Casino Development: How Would Casinos Affect New England's Economy? Boston, MA: Federal Reserve Bank of Boston (1995), 105-106.

MacDonald, R. "Panel Unit Root Tests and Real Exchange Rates." Economic Letters 50 (1996), 7-11.

Noble, N.R. and T.W. Fields. "Sunspots and Cycles: Comment." Southern Economic Journal 50 (1983), 251-254.

Office of Planning and Budgeting. "Casinos in Florida." Tallahassee, FL, 1995.

Politzer, R.M., J.S. Morrow, and S.B. Leavey. "Report on the Cost-Benefit/ Effectiveness of Treatment at the Johns Hopkins Center for Pathological Gambling." Journal of Gambling Behavior 1 (1985), 131-142.

Ramirez, M.D. "Public and Private Investment in Mexico, 1950-90: An Empirical Analysis." Southern Economic Journal 61 (1994), 1-17.

Rose, I.N. "Gambling and the Law: Endless Fields of Dreams." In R. Tannenwald (ed.), Casino Development: How Would Casinos Affect New England's Economy? Boston, MA: Federal Reserve Bank of Boston (1995), 118-146.

Schumpeter, J.A. The Theory of Economic Development. New Brunswick, NJ: Transaction Publishers, [1934] 1993.

Sheehan, R.G. and R. Grieves. "Sunspots and Cycles: A Test of Causation." Southern Economic Journal 49 (1982), 775-777.

Strazicich, M.C. "Are State and Provincial Governments Tax Smoothing? Evidence from Panel Data." Southern Economic Journal 62 (1995), 979-988.

Tannenwald, R. (ed.) Casino Development: How Would Casinos Affect New England's Economy? Boston, MA: Federal Reserve Bank of Boston, 1995.

Thompson, W.N. "An Economic Analysis of a Proposal to Legalize Casino Gambling in Ohio: Sometimes the Best Defense is to NOT Take the Field." Las Vegas, NV: UNLV manuscript (1996).

Thompson, W.N., R.C. Gazel, and D. Rickman. "Social and Legal Costs of Compulsive Gambling." Gaming Law Review 1 (1997), 81-89.

U.S. House of Representatives, Committee on Small Business. The National Impact of Casino Gambling Proliferation. Washington, D.C., 1995.

Vaughan, R.J. "Economists and Economic Development." Economic Development Quarterly 2 (1988), 119-123.

Walker, D.M. Sin and Growth: The Effects of Legalized Gambling on State Economic Development. Auburn, AL: Auburn University Ph.D. Dissertation, 1998a. - "Comment on 'Legal Gambling as a Strategy for Economic Development.'" Economic Development Quarterly 12 (1998b), 214-216.

Walker, D.M. and A.H. Barnett. "The Social Costs of Legalized Gambling: An Economic Perspective." Auburn, AL: Auburn University manuscript. 
Wright, A.W. "High Stakes Casinos and Economic Growth." In R. Tannenwald (ed.), Casino Development: How Would Casinos Affect New England's Economy? Boston, MA: Federal Reserve Bank of Boston (1995), 52-57.

Wu, Y. "Are Real Exchange Rates Nonstationary? Evidence from a Panel-Data Test." Journal of Money, Credit, and Banking 28 (1996), 54-63. 
